\title{
THE IMPACT OF EXCHANGE RATE ON ECONOMIC GROWTH IN ALGERIA Mohammed Touitou ${ }^{1}$, Yacine Laib ${ }^{2}$, Ahmed Boudeghdegh ${ }^{3}$
}

Abstract: The transmission of changes in the exchange rate to macroeconomic performance has led to debates about their impact, particularly on growth economic. Many economists consider the exchange rate as a transmission channel of economic policy for open economies. This article focuses to determining empirically the impact of the exchange rate on economic growth. For this, we will adopt an approach in terms of the vector autoregressive model (VAR) with four variables namely, the real effective exchange rate, economic growth, financial development with credit indicators and finally the money supply. The empirical results allow us to confirm our theoretical expectations that decline in the real effective exchange rate of the dinar increases the growth economy through public spending for consumption and is stimulated by oil taxation.

JEL Classification Numbers:F31, F43, C32, E51, DOI: 10.12955/cbup.v7.1381

Keywords: Exchange rate, Economic growth, VAR, Financial development, Money supply.

\section{Introduction}

The question of choice of exchange rate regime is a major importance for the economic development of a country. The debates around this subject have been posed with more intensity since the works of (Friedman, 1953)and (Robert, 1995)who have placed this issue at the center of international macroeconomics. Moreover, as a result of the collapse of the Bretton Woods system, countries have now been free to adopt the exchange rate regime (fixed, floating or intermediate) best suited to their needs. Both theoretical and empirical investigations have attempted to identify the most appropriate exchange rate regime for an economy by examining its effects on macroeconomic variables.

In fact, the exchange rate policy of each country should favour a system whose objectives and goals are to achieve faster, stable and sustained growth. Referring to this principle, Lahrèche-Revil (1999) advance that the exchange rate regime affects the stability and competitiveness of the state economy. Indeed, the exchange rate plays a strategic and considerable role for any company that exports or imports, or any financial or non-financial institution that lends, and borrows on foreign markets.

Ross (1997), defined how the degree of development of the measurable financial system by its ability to mobilize savings, facilitate the distribution of capital and improve risk management could promote growth through its effects on the accumulation of capital.

The first current points out that the adoption of an unsustainable exchange rate regime is detrimental to economic growth, Frankel (1997) indicates that fixed exchange rate regimes are more advantageous compared to floating exchange rate regimes, especially currency unions that encourage investment and trade, and therefore promote growth (Jeffrey, 2004). According to the empirical results obtained by Andrew (2000), monetary unions would have a positive effect on international trade and exchange rate volatility. Susan (1996)also suggests that the flexibility of the exchange rate regime is a source of exchange rate volatility that increases the profitability risk of export transactions, investments and therefore weakens growth.

In general, the choice of a good exchange rate regime for rapid economic growth is not yet decided. Some authors believe that a fixed and stable exchange rate regime generates rapid growth, and the shift to flexibility is associated with increased volatility in exchange rates. Others argue that fixed exchange rate regimes are not able to absorb shocks that misalign the exchange rate, but the adoption of floating regimes may reduce the likelihood of a sustainable imbalance in the exchange rate likely to affect the exchange rate, which cause an economic crisis and a recession. The second current shows that the misalignment of the real exchange rate affects the economic growth and welfare of a nation. A mispricing of the exchange rate can influence economic growth, for example, an overvaluation of the national currency beyond equilibrium. Overvaluation negatively affects the international competitiveness of domestic products in the short term, i.e. to say it penalizes the trade balance and thus harms economic growth.

Finally, on the impact of exchange rate change on economic growth, theoretical and empirical work is involved. Mishkin (1996)points out that the exchange rate is a channel that plays an important role in

\footnotetext{
${ }^{1}$ Faculty of Economics and Business, University of Algiers 3, Algiers, Algeria, touitoutouitou@ yahoo.fr

${ }^{2}$ Faculty of Economics and Business, University of Algiers 3, Algiers, Algeria,m.laibyacine18@gmail.com

${ }^{3}$ Faculty of Economics and Business, University of Jijel, Jijel, Algeria, lamrahm@ yahoo.fr
} 
the way monetary policy affects the national economy, a depreciation of the national currency lowers the price of domestic goods in relation to foreign goods, which translates into an increase in net exports and hence in overall output (Barry, 2007).

\section{Exchange Rate and Economic Growth}

The link between exchange rate regimes and economic growth has been invested by several recent studies. The first study presented here was conducted by Rizzo (1998), which examines the impact of exchange rate regimes on growth in Latin America, the Mediterranean and South-East Asia. At first, the author excludes the growth rate of trade. The study performed a logarithmic regression of the GDP per capita on a fixed exchange rate proxy variable, lagged growth in public consumption in approximate terms of the fiscal impulse, the investment rate, the variability of the terms of the assimilated exchange the three-year sliding pattern of the World Bank's terms of trade and the development index.In a second step, the study integrates the rate of growth of foreign trade into the model. The results of the different regressions do not suggest a strong overall link between the exchange rate regime and the GDP per capita growth.

The second empirical result that we analysed is that of Amvouna (1998), which has the following objectives. First, it checks how the various exchange rate regimes put in place in African countries have affected their economic performance. Second, given the international economic environment of the time, mainly the new monetary policy of the European Union and also the globalization of the economy, the author seeks to determine what would be the best currency exchange for the African countries. The results reveal that the investment rate, the rate of variation in the terms of trade, the rate of growth of the labour force, the solitary attachment to a currency and free float contribute significantly to increasing GDP. On the other hand, the fiscal deficit and the float-adjusted negatively affect growth. However, float-adjusted does not have a significant impact on economic growth.

Thus, following an analysis of 25 emerging economies covering the period 1973-1998, and using their own classification, Bailliu et al (2001) found that floating exchange rate regimes had faster economic growth, but only for countries that are relatively open to international capital flows and, to a lesser extent, to countries with well-developed financial markets. Similarly, using the annual data for 183 countries covering the period 1974-2000Levy Yeyati and Sturzenegger (2003) noted that more rigid exchange rate regimes are associated with lower growth in developing economies while in the industrialized economies, the type of scheme has no noticeable effect on growth.

Edwards (1993),has studied the impact of exchange rate regimes on inflation on a sample of 52 developing countries during the period 1980-1998. The results show that countries that were in a fixed exchange rate regime had lower inflation rates than those in a flexible exchange rate regime. Mundell (1995)compared economic growth in industrialized countries before and after the collapse of the Bretton Woods system. It shows that economic growth was much faster during the first period when exchange rates were fixed. As for their findings, Ghosh et al (1997)used annual data to test this relationship. This study does not fail to distinguish a conclusive result regarding the effect of the exchange rate regime on economic growth.

\section{Exchange Rates and Economic Growth in Algeria}

The nominal exchange rate has had two major periods; the first period of 1990-1996 marked by a continuous devaluation of the dinar. This devaluation was the necessary condition of the IMF when it signed the first standby agreement on May 31, 1989 to obtain its support for the repayment of external debt or even economic recovery. Then the second period from 1996 when the exchange rate was stable following the adoption of the managed float and the creation of an interbank foreign exchange market. In addition, the real exchange rate recorded a deviation from the nominal exchange rate because of the massive rise in the inflation rate during the first period, as exchange rate came closer in the second period following the fall in the level of inflation. This confirms the efforts made by the Bank of Algeria in terms of monetary and exchange rate policy.

From the figure below, Algerian economic growth has had three major periods since 1990. The first recession period of 1990-1994 is characterized by negative growth rates of GDP. These mediocre rates are a consequence of the deterioration in hydrocarbon export earnings generated by the 1986 oil shock and the external debt crisis. Then, the second period of 1995-2001 was called an economic recovery, the growth of the Algerian economy remained modest and below its potential with an annual average of $3.4 \%$ and a decrease in $1997(1.1 \%)$ due to a decline in agricultural production. Finally, the last 
period of 2002-2015 was marked by an acceleration of growth following the launch in 2001 of a threeyear program to support economic recovery as well as the pursuit of economic reforms and especially by the reconstitution of foreign exchange reserves which have consolidated the balance of external payments.
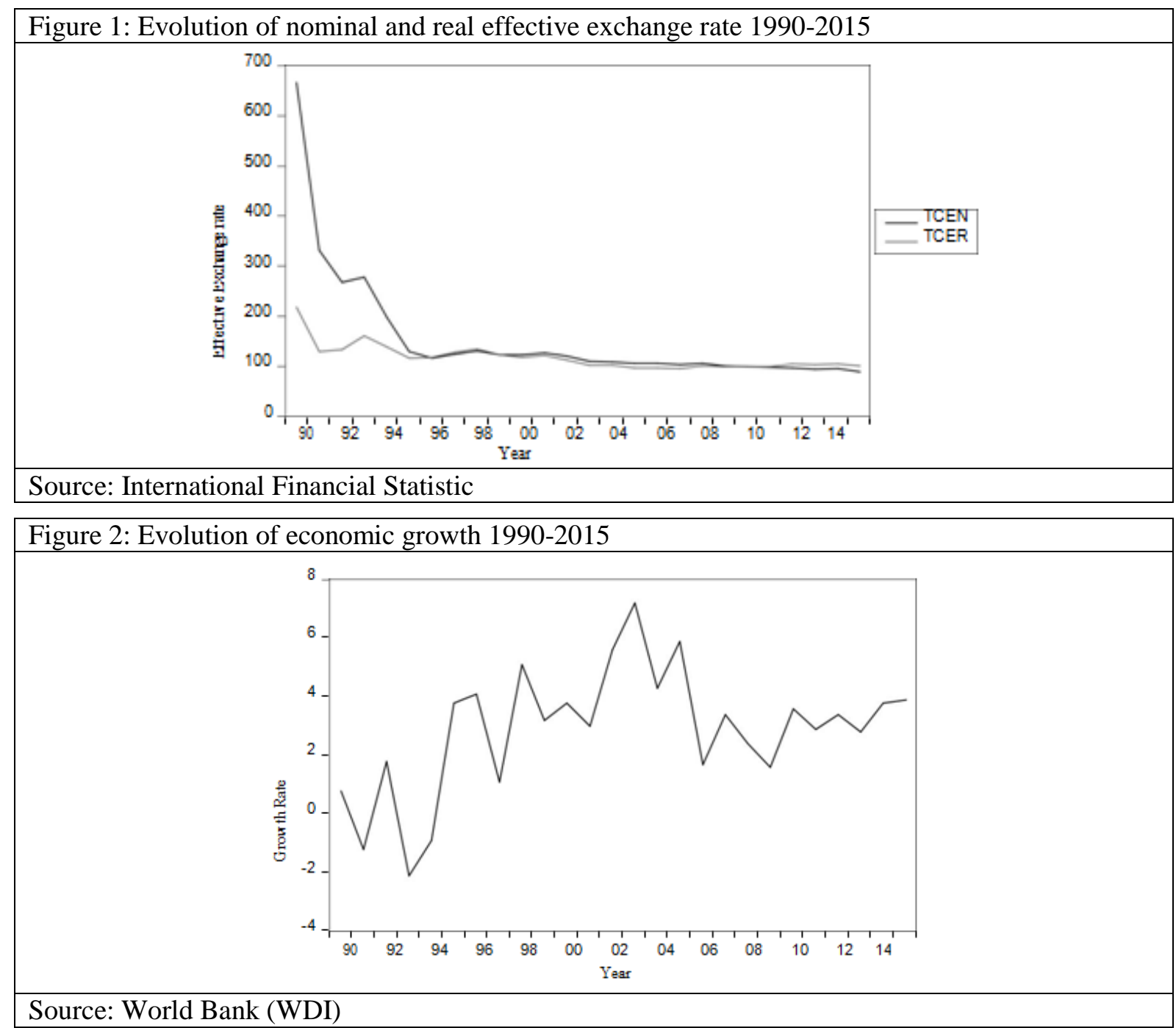

\section{Methodology and Empirical Analysis}

We proceed to analyze the impact of the exchange rate on economic growth with the use of a four variable VAR model (autoregressive vector model); exchange rate, money supply, financial development and economic growth. The estimation method used is least squares with the software Eviews9. The VAR analysis of the exchange rate impact will allow us to identify the structural shocks of the variables and to decompose their effect on growth following the Choleski decomposition. Thus, the impulse response functions allow us to detect how economic growth responds to exchange rate shocks.

Presentation of the data: For this study, we use a time series covering the period from 1990 to 2015, i.e. 26 observations. Our sources of data are numerous: the International Financial Statistics of the IMF, the Bank of Algeria and the World Bank (World Development Indicators). In our study, we assume that only the exchange rate influences economic growth, it is inefficient and does not reveal the real impact. Other variables can influence growth that is why we extend our multivariate model to get closer to theory and reality. We retain then, the real effective exchange rate quoted ascertain (since Algeria is a country trading with several partners, it is useful to take into account an effective exchange rate that takes into account the weight of different currencies of transaction), the broad money growth rate M2, domestic credit as a percentage of GDP as an indicator of financial development, and the GDP growth rate. 
Model specification: Before proceeding with the empirical estimation of the model, we must first specify among other things, the equation:

$$
G D P=\beta 1+\beta 2 R E E R+\beta 3 F D+\beta 4 M M+\varepsilon
$$

REER : The real effective exchange rate, $F D$ : financial development, $M M$ : money block. $\beta 1, \beta 2, \beta 3, \beta 4$ : represent the coefficients of the model; $\varepsilon$ : represents the error term of the equation.

However, since we work with a time series, it is necessary to make sure of their stationarity. The latter is a necessary condition for avoiding dummy relationships.

Stationary test: For this purpose, we will adopt the Augmented Dickey-Fuller (ADF) and Phillips Perron (PP) tests, which take into account the possible autocorrelation of the differentiated series via a correction using delayed values. These tests identify the order of integration of the series. When the series is stationary in level its order of integration is (0) on the other hand if it admits a stationarity in difference, the order of integration can go from 1 to J.The results of the Augmented Dickey-fuller (ADF) and Phillips-Perron (PP) (see annex) tests indicate that:

The real effective exchange rate and money block are stationary in level since the t-statistic -7.97 and 4.74 are respectively below the critical value -3.60 at the threshold of $5 \%$ and their probability is less than 5\%. On the other hand, gross domestic product and credits are not stationary in level since their statistical values -3.38 and 0.61 are respectively greater than the critical value -3.60 and their probability is greater than 5\% (0.07 and 0.99).

After examining the various tests, the non-stationary series became stationary after a first difference estimator. We can therefore conclude that the real effective exchange rate and money supply series are integrated of an order of 0 while the series gross domestic product and the credits (FD) are integrated of an order of 1 .

Cointegration test: Since the variables of our model are not integrated of the same order, we can say that there is no cointegration relation in the sense of Granger. So we cannot estimate the impact of the exchange rate on growth, and neither can we construct a Vector Error Correction Model (VECM). That said, the model compatible with our empirical study is the vector autoregressive model (VAR).

\section{Determining the number of delays P:}

The determination of the VAR delay number was made using the information criteria.

\begin{tabular}{|ccccccc|}
\hline \multicolumn{6}{|l|}{ Table 1: Number of delays of the VAR model } \\
\hline
\end{tabular}

The analysis of the table shows that referring to the different criteria, the minimum for Schwarz and Akaike corresponds to $p=2$, so the number of delays to retain which minimizes the information criteria is 2 . We therefore retain a VAR (2).

Model estimation: After checking the stationarity of the time series and determining the number of delays, we move on to the estimation of the VAR model (2) to analyze the impact of the exchange rate on economic growth and to see its reaction following a shock on the exchange rate. The results of the estimation allows us to write the equation of each variable according to its past values and the past values of the other variables. In our model that deals with the impact of the exchange rate on growth, we are interested in estimating only the equation of our variable to explain namely economic growth. The equation obtained is thus:

$$
\begin{array}{rl}
D(G D P)=-1,006 & * D(G D P(-1))-0,45 * D(G D P(-2))-0,12 * R E E R(-1)+0,16 \\
& * R E E R(-2)+0,14 * D(F D(-1))+0,01 * D(F D(-2))+0,005 * M M(-1) \\
& +0,02 * M M(-2)-4,98
\end{array}
$$

$R^{2}=74,22 \quad$ F-stat $=5,03$

The results of the estimation show that the parameters of the model are globally significant. The 
coefficient of determination $\mathrm{R}^{2}$ is equal to $74.22 \%$. This means that model-independent variables explain $74 \%$ of growth while the rest (26\%) is explained by other variables that were not taken into the model. Our model is globally significant given the value of the F-Statistics (5.03) which is greater than the value tabulated at the threshold 5\% (2.59). It is therefore concluded that the model is retained.

Validation of the model: To continue the rest of the work on the estimated model and to interpret the results obtained, it is essential to carry out some tests in order to validate the model. There are three tests: the stationarity test, the normality test and the autocorrelation test.

Stationary of the model: The stationary of the VAR model (2) is tested by the inverse of the characteristic polynomial roots. If the inverse of all the roots is within the unit circle, then the stationarity conditions of the model are verified.

\begin{tabular}{|l|l|l|l|}
\hline Figure 3: Invers roots of AR characteristic polynomial \\
\hline
\end{tabular}

The inverse of all the roots is in the unit circle according to the stationarity test. The stationarity conditions are verified; the VAR model (2) is stationary and is therefore retained.

Normality test: This validation test of the VAR model makes it possible to see if the residuals (error terms) of the model follow a normal distribution. In our study, we refer to the Jarque-Bera normality test. The following table represents the results of the normality test of the model:

\begin{tabular}{|c|c|c|c|c|}
\hline \multicolumn{5}{|l|}{ Table 2: Normality test } \\
\hline & \multicolumn{4}{|c|}{$\begin{array}{l}\text { VAR Residual Normality } \\
\text { Tests } \\
\text { Orthogonalization: Cholesky (Lutkepohl) } \\
\text { Null Hypothesis: residuals are multivariate } \\
\text { normal } \\
\text { Date: } 12 / 16 / 16 \text { Time: } 20: 13 \\
\text { Sample: } 1990 \\
2015 \\
\text { Included observations: } 23\end{array}$} \\
\hline & Component & Jarque-Bera & $\mathrm{Df}$ & Prob. \\
\hline & $\begin{array}{l}1 \\
2 \\
3\end{array}$ & $\begin{array}{l}1.947903 \\
1.959534 \\
0.091800\end{array}$ & $\begin{array}{l}2 \\
2 \\
2\end{array}$ & $\begin{array}{l}0.3776 \\
0.3754 \\
0.9551\end{array}$ \\
\hline & 4 & 2.549161 & 2 & 0.2795 \\
\hline & Joint & 6.548399 & 8 & 0.5860 \\
\hline
\end{tabular}

The normality test results on the model indicate that the variables follow a normal distribution since Jarque-Bera probability $(0.5860)$ is greater than $5 \%$.

Autocorrelation test: The lack of autocorrelation between errors is one of the necessary conditions for validating an econometric model. To do this an autocorrelation test must be made. In this study, we refer to the Lagrange LM multiplier test.

Note that there is no autocorrelation between model errors since the probabilities are greater than 5\%.

The various tests carried out show that the model is stationary; the errors are not auto-correlated and follow the normal law. Therefore, the model is validated and retained; it can be the subject of economic analysis and interpretation. 


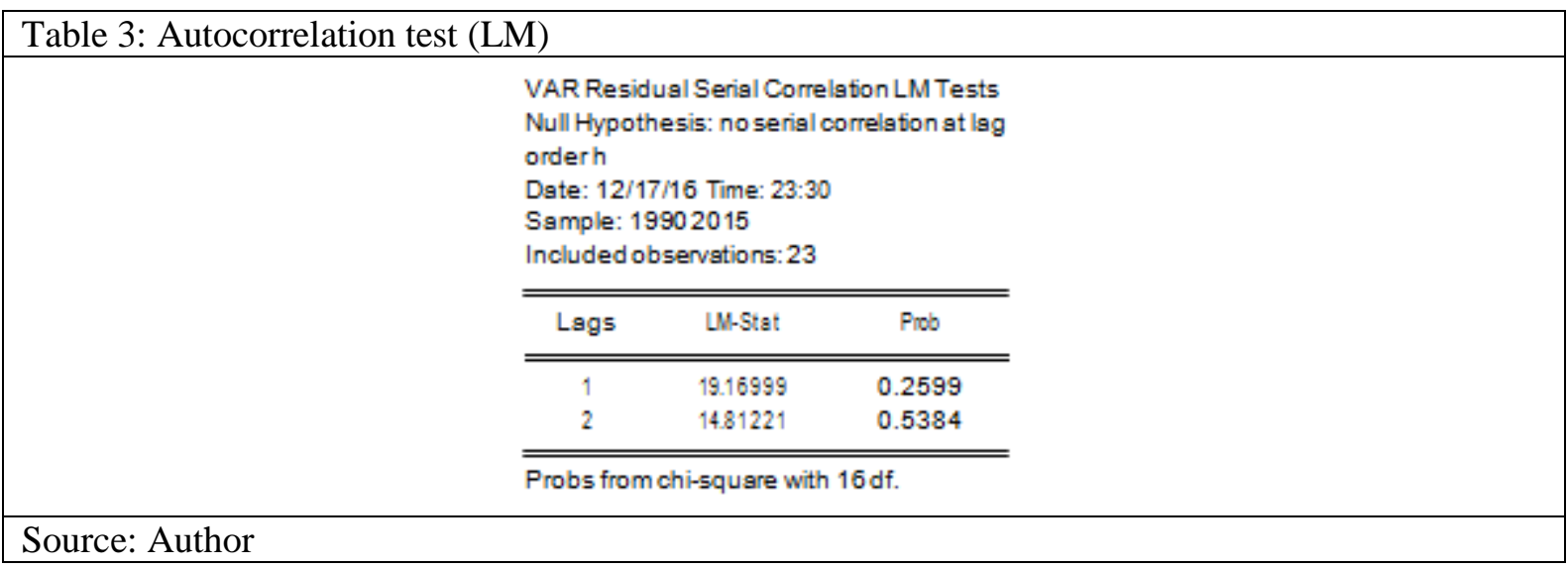

Result and interpretation: We will present the impulse response functions and the variance decomposition of forecast errors to determine the relative importance of each shock in explaining fluctuations in economic growth. We proceed last to the Granger causality test.

Detection of the instantaneous impact of pulse functions: Impulse response analysis is one of the main uses of VAR processes in empirical applications. It is therefore interesting to examine the impact of shocks in such a framework.

Examination of the magnitude of transmission of shocks to the exchange rate, financial development (credit) and money supply to growth allowed us to measure the impact of a depreciation of the exchange rate, an increase in the money supply and credits. The accumulated impulse responses represented by continuous blue lines are presented over a 10-year horizon.

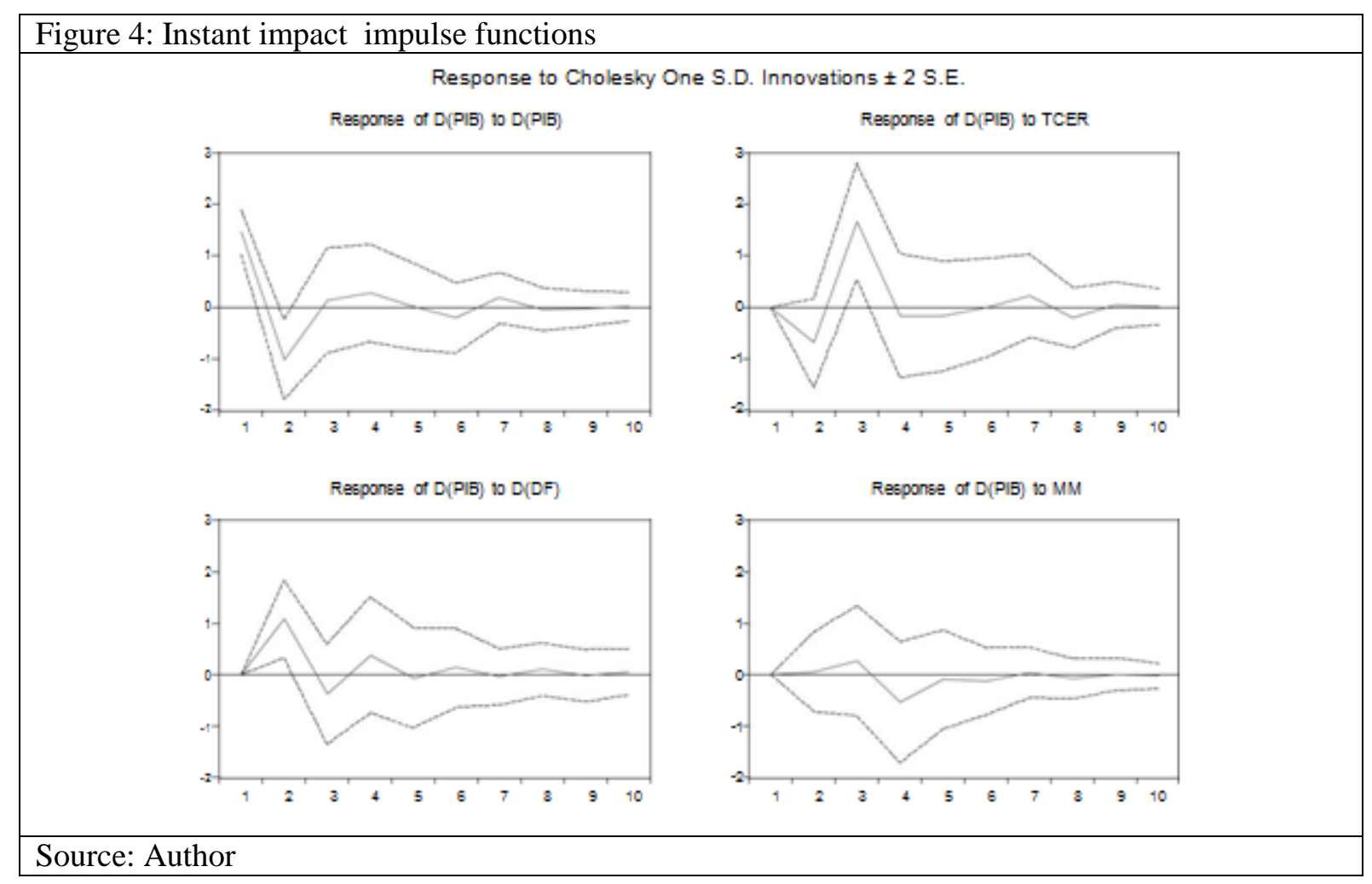

All shocks are standardized to $1 \%$, and therefore, the vertical axis indicates the percentage of the approximate change in growth in response to a $1 \%$ shock on the exchange rate, the money supply and the financial development (credit). The results of the impulse functions of the model are shown in the figure 4.

It is generally noted that the impact of shocks on the variables fades at the end of the 10th period; we note that the shocks are transient that is to say that the variables regain their long-term equilibrium.

A shock on the real exchange rate results in positive and negative alternating effects on economic 
growth during the whole period. These effects are manifested by periods of increase $(3,7,9,10)$, in other words a fall in the exchange rate stimulates economic growth (1.67-0.22-0.04-0.01). This exchange rate channel is based on the idea that a fall in the real value of the national currency increases economic growth through the petroleum taxation that stimulates public spending since the Algerian economy is very dependent on hydrocarbons. This effect diminishes at the end of the period. As for the periods of decline $(2,4,5,6,8)$, the shock has had a negative effect on growth.

A shock on financial development (credit) has a positive effect from the second year (1.08), however, an increase in credit stimulates production and investment and thus promotes economic growth. This result is validated by the work of Schumpeter, who considers that bank credit is the most decisive element of economic development, which thus favors access to capital goods needed to increase production. There is also the work of Mc Kinnon (1973) who points out that the efficiency of the development of the financial system stimulates growth. The effect becomes negative in the fifth year (0.06), this may be explained by a rise in inflation during this period which has had an impact on growth. Finally, it stabilizes over the long term reaching 0.05 .

Finally, a shock on the growth of money supply appears from the second year and produces a positive effect $(0.05)$ on growth but is not significant, however this effect becomes negative to gain its initial value. This says that the money supply does not stimulate economic growth. This result is confirmed by neoclassicals who emphasize that money is neutral and has no effect on real variables and therefore on activity and growth.

To better discern the transmission of exchange rate shocks to inflation, the analysis of variance decomposition is used.

Decomposition of variance of forecast errors: The analysis of the variance decomposition of the forecast error (Choleski decomposition) completes the study of impulse response functions. The contribution of different shocks to the variance of the forecast error is presented in the table below.

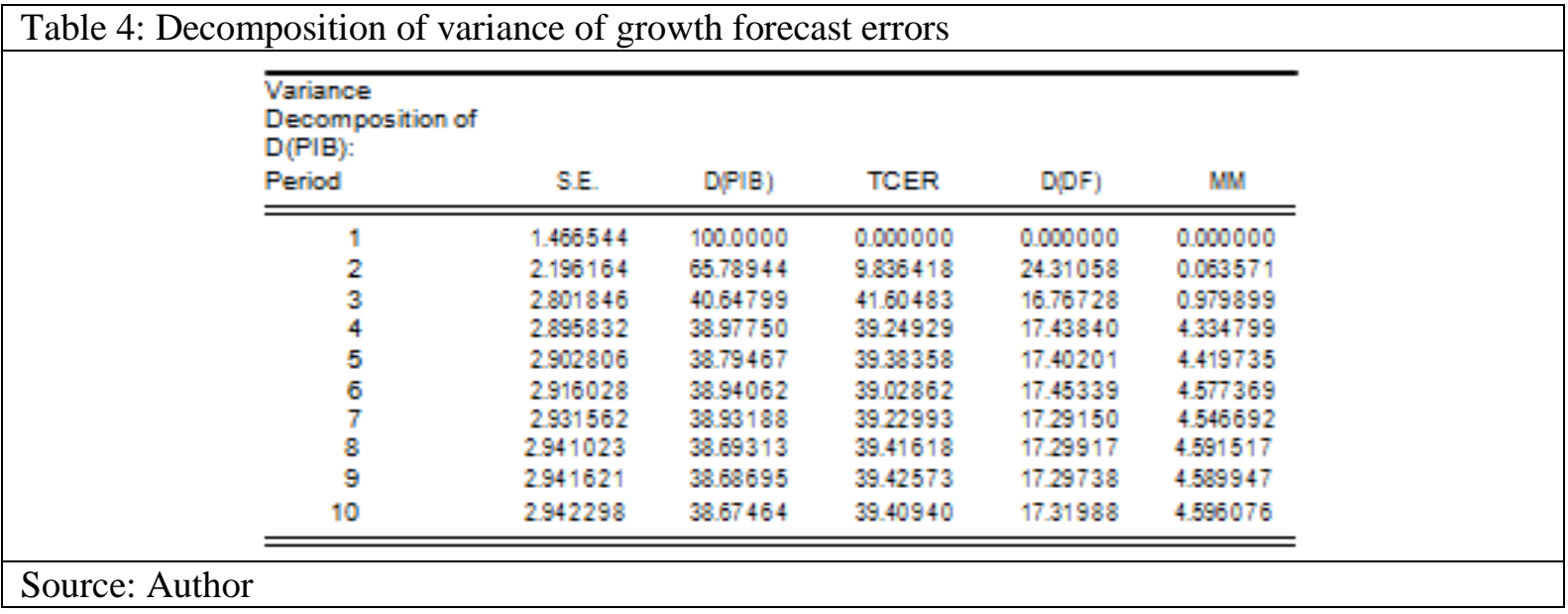

The decomposition of the variance indicates that over a one-year horizon, the variance of the forecast error of growth (GDP) is due only to its own innovations (100\%), it is only from the second year that the contribution of the other variables increases. In other words, the variance of the forecast error of growth (GDP) is $65.78 \%$ due to its own innovations, $9.83 \%$ to that of the exchange rate, $24.31 \%$ to that of financial development FD (credits) and $0.06 \%$ to that of the money supply. From the fourth year, the contribution of all variables remained almost stable.

It is therefore concluded that the exchange rate contributes a good deal in determining the variance of the forecast error.

Granger causality test: From this test, we can determine the causal link between the explanatory variables of the model and the variable to explain namely economic growth. The results of the test allow us to conclude that: it is the real effective exchange rate (REER) and the financial development (FD) measured by the credit that cause Granger economic growth because their probability is less than $5 \%$ (0.0001 and 0.0041 respectively). However, the money supply does not cause economic growth, as the probability $(0.69)$ is greater than $5 \%$. In addition, these three variables can jointly cause the growth rate of the GDP given the overall probability of less than 5\% (0.0004). 
On the other hand, such relations do not exist between the other variables. From this test, it is deduced that the economic growth in Algeria measured by the gross domestic product is caused by the real effective exchange rate and the credit taken as an indicator of financial development.

\section{Conclusion}

Any optimal economic policy uses transmission channels that prove effective to achieve its goals. These channels differ according to their speed of transmission of innovations. In the case of an open economy, the direct channel of the exchange rate plays an important role in the immediate transmission of impulses. This channel allows economic policy to influence macroeconomic performance, namely growth. Given that the exchange rate influences economic growth in interaction with other variables as indicated in the economic literature, it is crucial to see the response of growth to shock on these variables.

Thus, throughout the paper we proceeded to study the impact of the exchange rate on economic growth for the period 1990-2015 based on a four-variable VAR model. The estimation of the model shows that the model is a VAR2, which is globally significant, stationary and validated according to the different tests.Moreover, Granger causality indicates that it is the real exchange rate and financial development that causes growth in Algeria.

Cholesky's decomposition indicates that it is the exchange rate that contributes a good deal in determining the variance of the forecast error.

The study of implausible response functions shows that a depreciation of the exchange rate increases economic growth, and an increase in credits that reflect financial development increases growth. Regarding the money supply, an increase in it contributes very little to an increase in growth.

It is therefore concluded that the real effective exchange rate of the dinar contributes to the rise in economic growth through the petroleum taxation that stimulates public spending for consumption, since the Algerian economy is highly dependent on hydrocarbons. This result is part of Keynesian thinking, which stipulates a policy of economic recovery by supporting consumption.In addition, the financial development measured by domestic investment-oriented loans is also generating growth.

\section{References}

Amvouna, A. (1998). "Determinants of Trade and Growth Performance in Africa: A Cross-Country Exchange Rate Regimes,". EAGER Publication/BHM.

Andrew, R. (2000). « One Money, One Market: The Effect of Common Currencies on Trade ». Economic Policy, P 01.

Bailliu et al, B.-F. (2001). "Exchange Rate Regimes and Economic Growth in Emerging Markets." In Revisiting the Case for Flexible Exchange Rates. Proceedings of a conference held by the Bank of Canada,. Ottaw.

Barry, E. (2007). «The Real Exchange Rate and Economic Growth». the 8th annual conference of the W. Arthur Lewis Institute for Social and Economic Studies, (pp. P 01-18. ). Port of Spain.

Edwards, S. (1993). "Trade Policy, Exchange Rates and Growth.”. National Bureau of Economic Research Working Paper No. 4511.

Frankel, J. (1997). Regional Trading Blocs in the World Economic System. Washington, D.C: Institute for International Economics.

Friedman. (1953). The Case For Flexible Exchange Rates, in Essays in Positive Economics. Chicago: University of Chicago Press.

Ghosh et al, G.-M. (1997). "Does the Nominal Exchange Rate Regime Matter? Cambridge, Massachusetts: National Bureau of Economic Research.

Jeffrey, F. (2004). Experience of and Lessons from Exchange Rate Regimes in Emerging Economies. Macmillan Press. LAHRÈCHE-REVIL. (1999). The exchange regimes. Paris : Editions La Découverte.

Levy Yeyati and Sturzenegger, L. (2003). To float or to fix: Evidence on the impact of exchange rate regimes on growth. American Economic Review, 1173-1193.

Mishkin, F. (1996). "Understanding Financial Crises: A Developing Country Perspective," . Annual World Bank Conference on Development Economics (pp. 29-62.). Washington D.C: Michael Bruno and Boris Pleskovic, eds.

Mundell, R. (1995). “Exchange Rate Systems and Economic Growth.”. Rivista di Politica Economica, pp. 1-36.

Rizzo, J.-M. (1998). "The Economic Determinants of the Choice of an Exchange Rate Regime: A Probit Analysis,". Economics Letters, pp. 283-87.

Robert, M. (1995). Exchange Rate Systems and Economic Growth. Rivista di Politica Economica.

Ross, L. (1997). Financial Development nd. Economic Growth: Views and Agenda. Economic Literature, pp. 688-726.

Susan, C. (1996). « On becoming more flexible: Exchange rate regimes in Latin America and the Caribbean ». Journal of Development Economics, P 117-138. 